\title{
Microstructure and mechanical properties characterization of architectured copper aluminum composites manufactured by cold-drawing
}

\author{
C. Keller ${ }^{\mathrm{a}}$, F. Moisy ${ }^{\mathrm{b}}$, N. Nguyen ${ }^{\mathrm{a}}$, S. Eve ${ }^{\mathrm{b}}$, A. Dashti ${ }^{\mathrm{a}}$, B. Vieille ${ }^{\mathrm{a}}$, A. Guillet ${ }^{\mathrm{a}}$, X. Sauvage ${ }^{\mathrm{a}}$, E. Hug ${ }^{\mathrm{b}}$ \\ ${ }^{a}$ Groupe de Physique des Matériaux, UMR CNRS 6634, Normandie Université, avenue de l'Université, 76800 Saint-Etienne du Rouvray, France. \\ ${ }^{b}$ Laboratoire Crismat, UMR CNRS 6508, Normandie Université, 6 Bd Marechal Juin, 14050 Caen, France.
}

\begin{abstract}
The present study investigates the mechanical behavior of severely plastic-deformed $\mathrm{Cu}$-Al composite wires with different diameters and heat-treatments. Each composite holds 61 restacked copper-clad aluminum wires. The bimetal composites were cold-worked up to diameters ranging from $1 \mathrm{~mm}$ to $3 \mathrm{~mm}$, without any intermediate heat treatment. All the wires contain 61 hexagonal $\mathrm{Cu}-\mathrm{Al}$ fibers with a continuous copper network extended from the outer surface into the center of the samples. Tensile tests were then performed on the as-drawn and heat treated wires. The latter were treated at $400^{\circ} \mathrm{C}$ for $30 \mathrm{~min}$ and $6 \mathrm{~h}$. The heat treatments firstly induce recrystallization in both constituents, giving rise to a fine-grained microstructure and secondly prompt the formation of several intermetallics. Without heat treatment after processing, the architectured composites exhibit a ductility value similar to the conventional copper-clad aluminum wires and larger yield stresses compared to them, regardless of the diameter. The intermetallic compounds, forming as a result of heat treatment, affect the yield stress, ductility and strain hardening mechanisms. Finally, the results are discussed in terms of grain size, texture, intermetallics volume fraction and mechanical coupling between the phases.
\end{abstract}

Keywords: Metallic composite, wire, mechanical properties, intermetallic compounds, architectured microstructure

\section{Introduction}

The rising price of copper due to a huge demand for this material on the one hand, and its high density (8.96 g. $\mathrm{cm}^{-3}$ ) on the other hand, has convinced manufacturers to replace it, when possible, with aluminum. For instance, $\mathrm{Cu}-\mathrm{Al}$ bimetallic composites are currently used for such purposes. These composites can be obtained via various techniques including roll-bonding [1, 2, 3], friction stir-welding [4], stir casting [5], electroplating [6], cold-drawing [7], hydrostatic extrusion [8] or spark plasma sintering [9]. $\mathrm{Cu}-\mathrm{Al}$ composites can reduce weight and costs up to $40 \%$ and $30 \%$ respectively [10].

In the wire industry, the aforementioned $\mathrm{Cu}-\mathrm{Al}$ composite, known as Copper-Clad Aluminum Wire, abbreviated as CCAW or CCA, is commonly manufactured by cold-drawing using an outer copper case surrounding an aluminum core which are then simultaneously cold drawn to the desired diameter. In this composite, the copper shell provides 
good conductivity whereas the aluminum core serves as a light structural material with lower conductivity than copper. CCAs offer acceptable high conductivity for high frequency currents where the $\mathrm{Cu}$ phase acts as the current path because of the skin effect. However, at lower frequencies, the $\mathrm{Al}$ core also contributes to the electrical conductance reducing, in turn, the overall conductivity.

In the literature, various architectured CCAs have been proposed, creating a continuous copper network (or path) extended across the cross section, intented to increase the conductivity at low frequencies without having to reduce the volume fraction of aluminum. These new composites, manufactured by cold rotary swaging $[11,12]$ and also restacking cold drawing [13] were obtained using intermediate heat treatments (HT) aiming to recover ductility during the process. However, such heat treatments cause intermetallic compounds growth along the $\mathrm{Cu} / \mathrm{Al}$ interfaces which could be detrimental to the electrical conductivity and the mechanical behavior.

In a recent work, the authors proposed a new and promising restacking method, without any interoperational annealing, to fabricate an architectured $\mathrm{Cu}-\mathrm{Al}$ composite with a continuous copper network inside the cross section [14]. As dynamic recovery occurs during large plastic deformation, the resistivity of the above-mentioned composite in the as-cold-worked state was found to depend on neither the plastic deformation nor the wire diameter throughout processing. A post-processing heat treatment of these composites increases the resistivity only slightly, due to the formation of intermetallic compounds (IMCs). If the volume fraction of IMCs remains below $12 \%$, the increase in the resistivity stays below $10 \%$ [14]. In service, $\mathrm{Cu}-\mathrm{Al}$ wires could be subjected to high loads and hereby both good conductivity and proper mechanical properties are required. The large strains undergone by the wires during processing or the intermetallics formation associated with heat treatment can lead to early embrittlement of the wire making it unsuitable for industrial applications. Following the work of Hug and Bellido [15], a compromise between the mechanical properties (ultimate tensile strength and ductility) and the electrical conductivity could be achieved by suitable heat treatments.

The key objective of this work is hence to investigate the mechanical behavior of these new architectured copperaluminum wires under different heat treatment conditions. To this end, samples were cold-drawn to final diameters ranging from $3 \mathrm{~mm}$ to $1 \mathrm{~mm}$. They were then mechanically and microstructurally characterized in both as-drawn and heat treated states. Heat treatment conditions of $400^{\circ} \mathrm{C}$ for 30 minutes and 6 hours were considered in order to understand the role played by plastic deformation and the microstructure in terms of grain size, texture and IMCs volume fraction. The best mechanical properties were observed for the sample heat-treated at $400^{\circ} \mathrm{C}$ for 30 minutes. The volume fraction of IMCs and the final diameter were also found to influence the mechanical behavior, which is discussed in terms of grain size, texture and composite effect. 


\section{Elaboration procedure and material/mechanical characterization}

The composites were manufactured using 99.97\% purity OFHC (Oxygen Free High Conductivity) copper and $99.5 \%$ purity aluminum previously annealed during $3 \mathrm{~h}$ at $500^{\circ} \mathrm{C}$ for $\mathrm{Cu}$ and $300^{\circ} \mathrm{C}$ for $\mathrm{Al}$. The heat treatment operations were carried out in a secondary vacuum $\left(P_{\mathrm{O}_{2}}=10^{-6} \mathrm{mbar}\right)$ to prevent oxidation and to enable the recrystallization of both materials required to sustain the large strains involved by the process. The first step in the sample manufacture procedure is cold-drawing of a CCA wire up to a diameter of $1 \mathrm{~mm}$, using a copper tube of an outer diameter of 12 $\mathrm{mm}$, with a wall thickness of $2 \mathrm{~mm}$, and a $7.5 \mathrm{~mm}$ diameter aluminum rod. The die diameter was gradually decreased throughout the first step to avoid fracture during the process. Each wire took 34 passes for the diameter to change from 12 to $1 \mathrm{~mm}$. $611 \mathrm{~mm}$-CCA wires were then restacked into a $12 \mathrm{~mm}$-copper tube with a $1 \mathrm{~mm}$-thick wall and were further cold-drawn to obtain the intended architectured copper-clad aluminum composite wires (abbreviated as ACCA in the following lines). Three sets of wire samples of final diameters of $1,1.7$ and $3 \mathrm{~mm}$ were fabricated. The average plastic strain experienced by the wire during the process ranges between $\eta=7.37$ and $\eta=9.57$ (see table 1), estimated from equation 1, in which $S_{0}$ and $S$ represent the initial and final cross-sectional areas in the order given. Readers are referred to a previous article [14] for further details about the fabrication process. Figure 1 illustrates the typical cross section of an ACCA wire after the manufacture process observed by optical microscopy.

$$
\eta=\ln \left(\frac{S_{0}}{S}\right)
$$

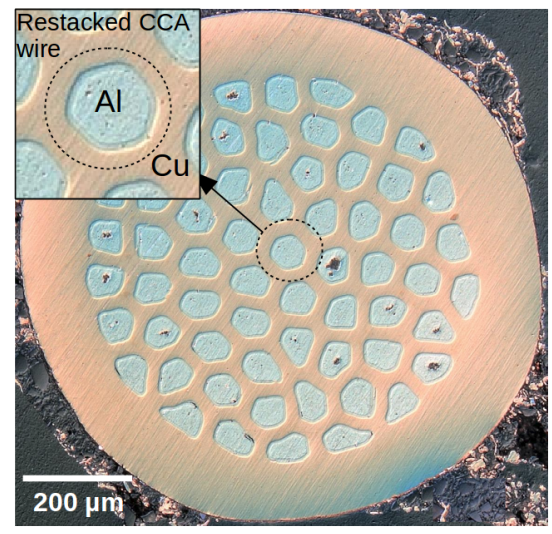

Figure 1: Example of an architectured copper-aluminum composite obtained by the restacking method based on cold-drawn.

In order to investigate the role played by the intermetallic compounds and the microstructure on the mechanical behavior, three kinds of wires were investigated: as-drawn (AD), annealed at $400^{\circ} \mathrm{C}$ during $30 \mathrm{~min}$ (HT1) and annealed at $400^{\circ} \mathrm{C}$ during $6 \mathrm{~h}$ (HT2). These heat treatments are expected to lead to different volume fractions of IMCs with a low initial dislocation density due to the recrystallization of the heavily strained $\mathrm{Al}$ and $\mathrm{Cu}$ grains. 
These wires were then subjected to tensile tests using specific wire grips in order to reduce stress concentration throughout the test. An electro-mechanical $10 \mathrm{kN}-\mathrm{MTS}$ C43 machine was used to perform the crosshead displacement-controlled tests at room temperature. Strain was recorded using a conventional extensometer with a gauge length of $25 \mathrm{~mm}$. During the test, the average strain rate was close to $10^{-4}$ in order to reduce viscous effects. Three tensile tests were carried out for each set of samples of different diameter and heat-treatment condition to take into account the experimental scattering of the mechanical properties. Nanoindentation tests (MTS NanoXP systems) were also performed on the cross section of the samples to obtain the hardness of each phase, prior to the tensile tests, for the different wire diameters and heat treatment conditions. Berkovich diamond tip (nominal tip radius of curvature of $20 \mathrm{~nm}$ ) was employed and all hardness measurements were displacement-controlled up to a penetration depth of $200 \mathrm{~nm}$. Spacing between each indent was set to $1 \mu \mathrm{m}$ in order to avoid interaction between plastics zones of each indent but also to capture the hardness of the IMCs. Before analyzing each sample, a preliminary calibration experiment on the same fused quartz specimen was performed to ensure reliable measurements.

The microstructure of all samples was analysed by Scanning Electron Microscope (SEM) coupled with Electron Dispersive Spectrum (EDS) and Electron BackScattered Diffraction (EBSD). Due to the small grain size, for the as-drawn samples, Transmission Electron Microscopes (TEM) using different analysis modes, i.e. ASTAR (FEI TECNAI) and STEM (Scanning Transmission Electron Microscopy - JEOL ARM 200F) were also employed for the microstructure analysis. Fracture surfaces of the samples were also analysed by SEM in order to investigate the fracture mechanisms. For SEM and nanoindentation, samples were prepared by conventional SiC polishing followed by a final step of vibratory polishing or electropolishing.

\section{Results}

\subsection{Microstructural characterization}

The phase, grain size and texture of all ACCA samples of different diameters and heat treatment conditions (AD, HT1 and HT2) were determined using SEM and TEM (for the sake of consiceness, only a few analysis are reported in the following paragraphs). Figure 2 illustrates the initial microstructure of the as-drawn sample, observed by TEM. A typical $\mathrm{Cu} / \mathrm{Al}$ interface, at higher magnification, is indicated on figure 2(a) in the bright field STEM mode. Copper is in the top left area of the image whereas aluminum is in the bottom right corner. As shown in this figure of the cross sectional plane, grains are equiaxed in the cross-section, with an average spacing between boundaries of around a few hundred nanometers for each phase. Figure 2(b) shows at higher magnification, in bright field STEM mode, of a typical $\mathrm{Cu} / \mathrm{Al}$ interface. As reported in a previous article [16], no IMC could be detected along such an interface, except for a small fraction of nanoscaled $\mathrm{Al}_{2} \mathrm{O}_{3}$ resulting from the cold-drawing process. The grains are mostly 
dislocation-free, however, few grains also exhibit dislocation walls/cells (encircled in the figure 2(b)).

Grain orientation maps and pole figures of each phase were acquired, from the cross section, using ASTAR analysis. $\mathrm{Cu}$ and $\mathrm{Al}$ (001), (011) and (111) pole figures are plotted in figures 2(c) and figure 2(d) for the $3 \mathrm{~mm}$ diameter as-drawn sample, respectively. A fiber texture with major $<111>$ and minor $<001>$ orientations, was characterized for both phases, in agreement with the results from previous researchs on the influence of cold drawing on the texture of pure $\mathrm{Cu}[17,18]$ and pure $\mathrm{Al}[19]$. Figures 2(e) and 2(f) represent the $\mathrm{Cu}$ and $\mathrm{Al}$ grain orientation maps, respectively. The post-processing fraction of very low angle grain boundaries (misorientations $\leq 5^{\circ}$ - VLAGBs) characterized in each phase, is about $20 \%$. This feature is in accordance with the results from the study conducted on wire drawing and accumulative roll bonding of pure copper by Hanazaki et. al. [20]. The fraction of high angle grain boundaries is about $10 \%$.

Figure 3(a), which shows the SEM-EDS map of a heat-treated sample, highlights the copper and aluminum distribution in the cross section of a 3-mm diameter ACCA wire after HT2. InterMetallics Compounds (IMC) are clearly exhibited. For the same sample, figure 3(b) and figure 3(c) illustrate the $\mathrm{Cu}$ and $\mathrm{Al}$ grain orientation maps, respectively. Preferred grain orientations are clearly visible in both phases. As reported in the as-drawn condition, these preferential orientations lead to a large volume fraction of VLAGBs presented in figure 3(d) for $\mathrm{Cu}$ and $\mathrm{Al}$. A large amount of annealing twins were also formed in copper because of its low stacking fault energy.

Figure 4 illustrates the three principal IMCs, $\mathrm{Al}_{4} \mathrm{Cu}_{9}, \mathrm{AlCu}$ and $\mathrm{Al}_{2} \mathrm{Cu}$ that have been characterized in two previous papers for the same samples [14, 16], in agreement with literature [21, 22, 23, 24]. For short heat treatment conditions $\left(300^{\circ} \mathrm{C}\right.$ during $15 \mathrm{~min}$ to enable the TEM observation of the IMC interface), the bright field TEM image of a $1.7 \mathrm{~mm}$ diameter ACCA (figure 4(a)) reveals that the AlCu layer is the thinnest one. This trend is not modified for longer heat treatment duration as illustrated in figure 4(b) for a $1.7 \mathrm{~mm}$ ACCA wire submitted to HT2. In this case, the thickness of the IMCs layer is about $25 \mu \mathrm{m}$. More details about the IMCs characterization can be found in a previous article [16].

(001), (011) and (111) pole figures of the cross section for a $3 \mathrm{~mm}$-diameter ACCA wire, heat-treated under HT2 conditions, are plotted in figure 5(a) and figure 5(b) for copper and aluminum, respectively. The same pole figures for a $1 \mathrm{~mm}$-diameter ACCA wire, after HT2, are plotted in figure 5(c) and figure 5(d) for $\mathrm{Cu}$ and $\mathrm{Al}$ in the order given. Because fewer grains were analyzed for aluminum, discret spots, rather than a continuous distribution (as seen for $\mathrm{Cu}$ ), appear in the $\mathrm{Al}$ pole figures. Comparing the texture component and their related density for $\mathrm{Al}$ and $\mathrm{Cu}$ for each heat treatment, figure 5 illustrates that the texture evolution depends on the material. 


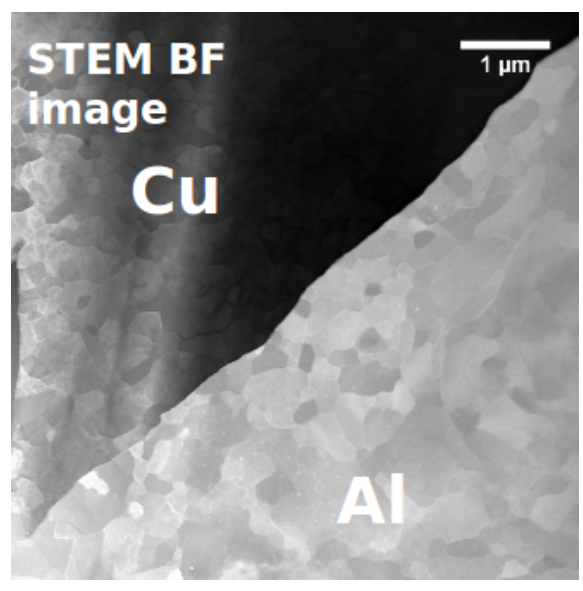

(a)
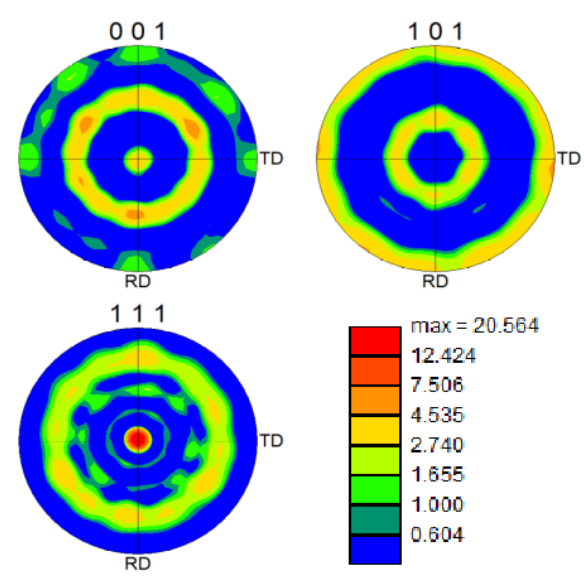

(c)

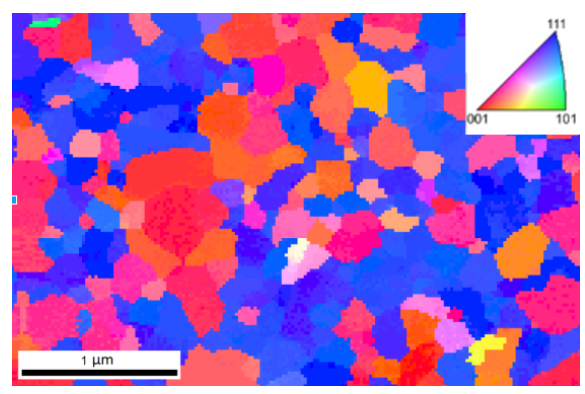

(e)

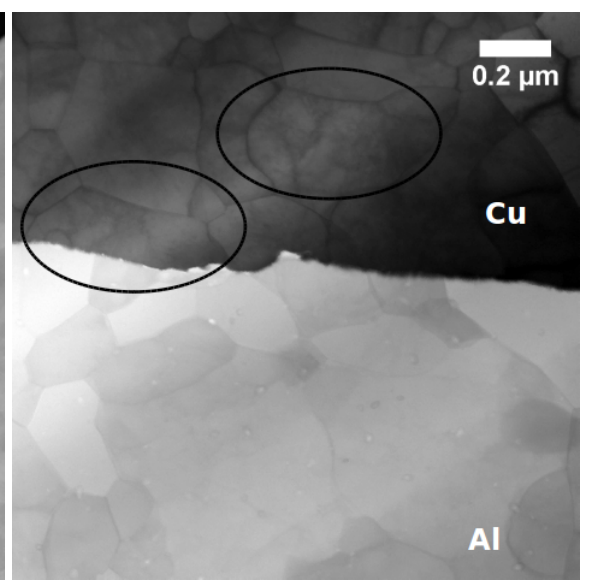

(b)
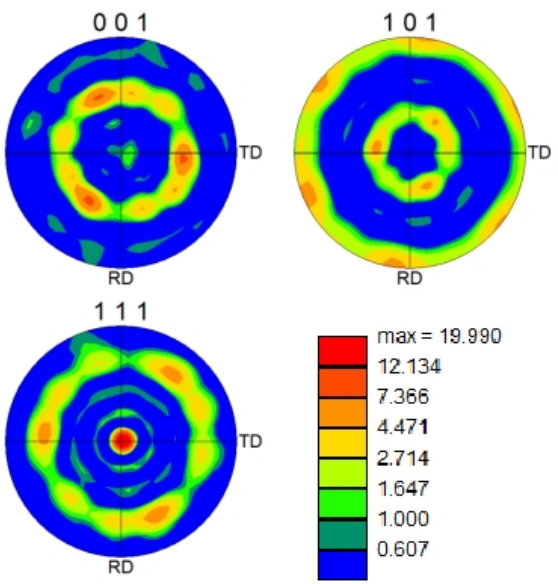

(d)

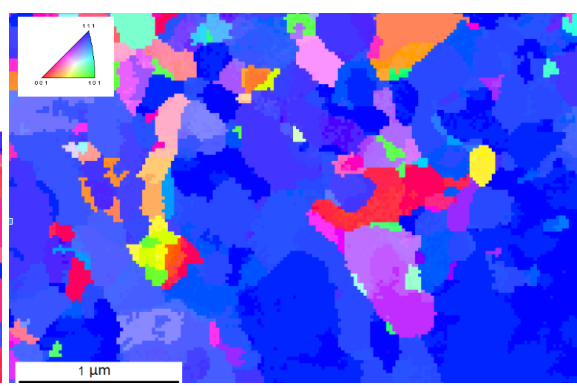

(f)

Figure 2: Microstructural analysis of a cross section of 3 mm-diameter architectured $\mathrm{Cu}$-Al wire composite in the as-drawn state: (a) and (b) STEM bright field images of $\mathrm{Cu}$ and $\mathrm{Al}$, (c) $\mathrm{Cu}$ and (d) $\mathrm{Al}$ (001), (011) and (111) pole figures, (e) $\mathrm{Cu}$ and (f) Al ASTAR grain orientation maps. 


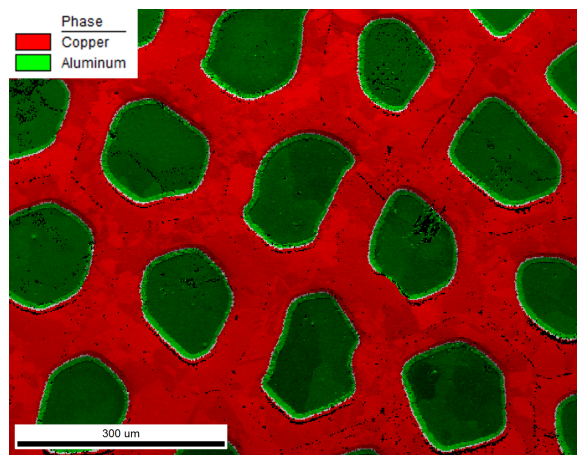

(a)

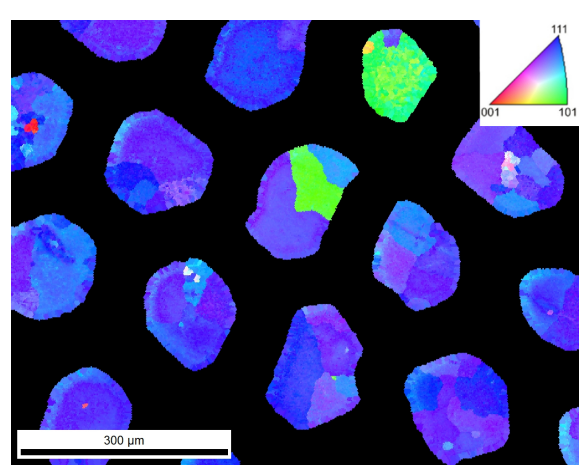

(c)

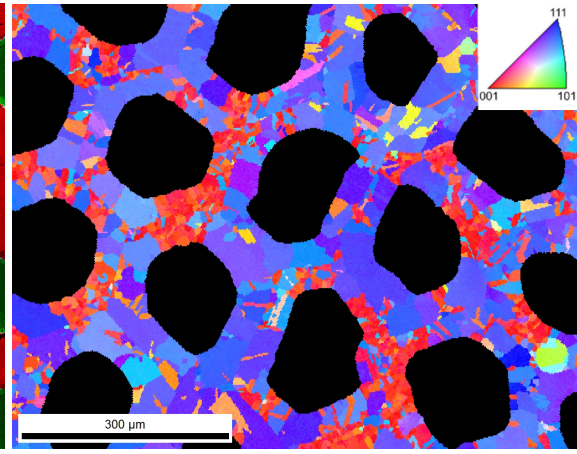

(b)

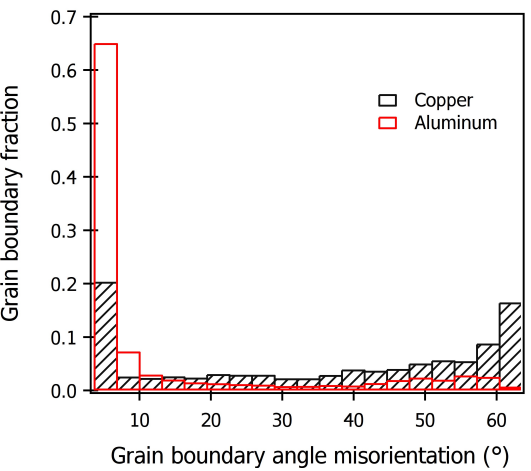

(d)

Figure 3: Microstructural analysis of a cross section of an architectured composite $\mathrm{Cu}-\mathrm{Al}$ ( $3 \mathrm{~mm}$ diameter) after heat treatment at $400{ }^{\circ} \mathrm{C}$ for $6 \mathrm{~h}$ : (a) SEM-EDS element map, (b) and (c) $\mathrm{Cu}$ and Al EBSD grain orientation maps respectively, (d) $\mathrm{Cu}$ and $\mathrm{Al}$ grain boundary misorientation diagram.

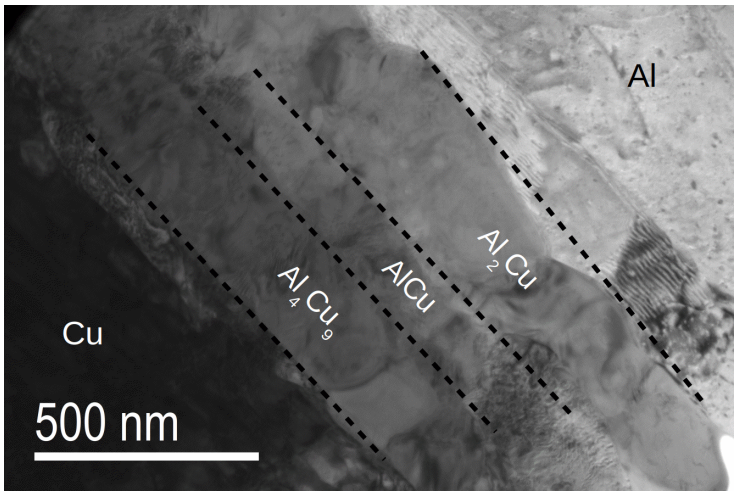

(a)

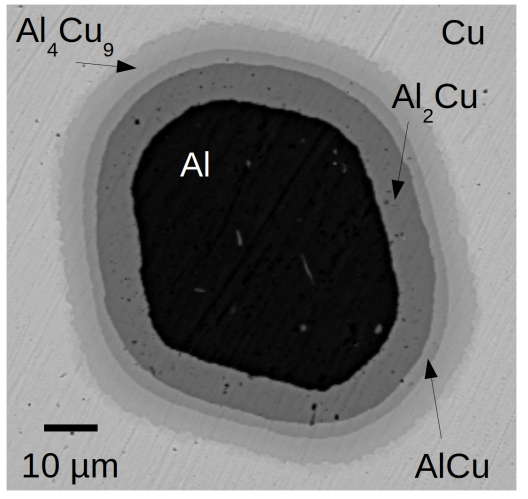

(b)

Figure 4: IMC observations for a $1.7 \mathrm{~mm}$ diameter ACCA wire : (a) bright field transmission electron microscope image for a short heat treatment at $300{ }^{\circ} \mathrm{C}$ during $15 \mathrm{~min}$ and (b) scanning electron microscope image, using backscattered electrons, for a heat treatment of $400{ }^{\circ} \mathrm{C}$ during $6 \mathrm{~h}$ (HT2). 

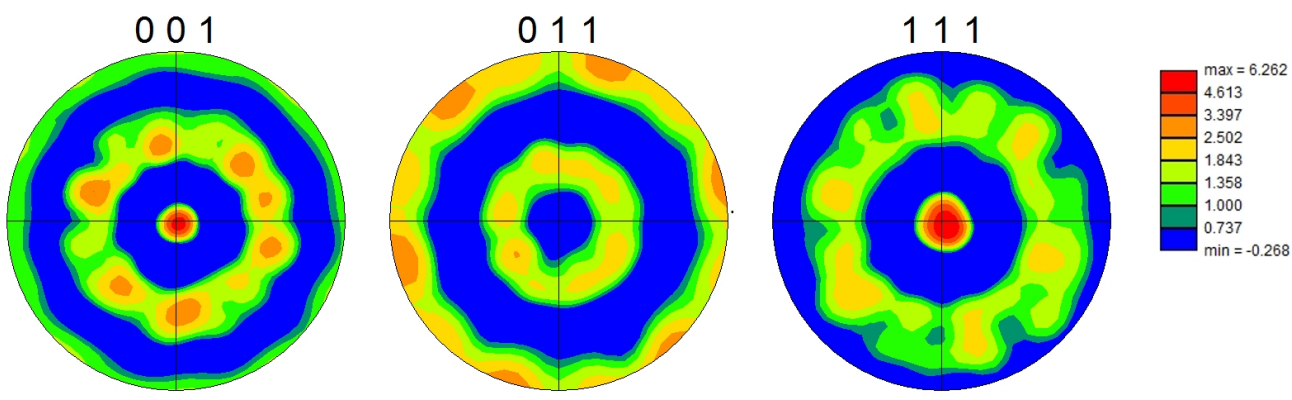

(a) ACCA $3 \mathrm{~mm} 400^{\circ} \mathrm{C}$ - $6 \mathrm{~h}$ - copper
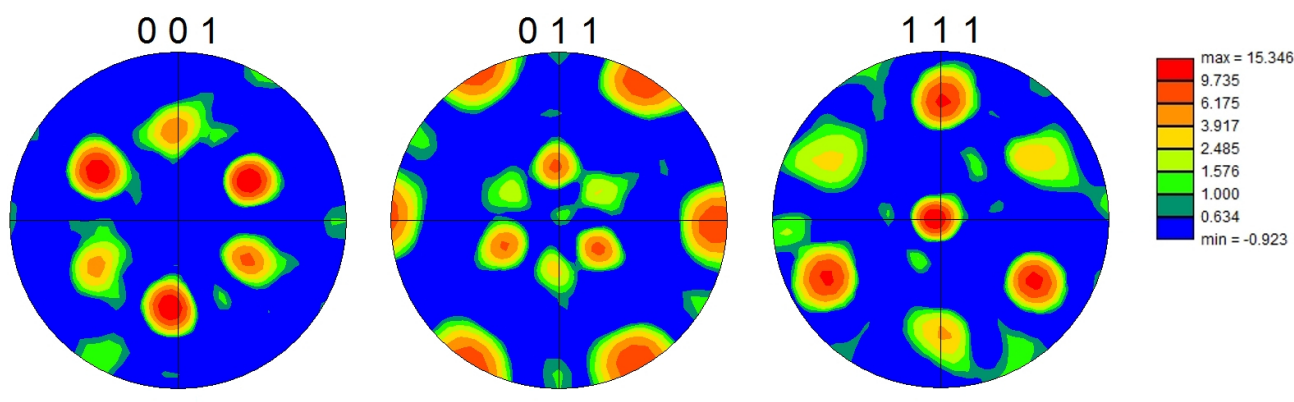

(b) $\mathrm{ACCA} 3 \mathrm{~mm} 400^{\circ} \mathrm{C}-6 \mathrm{~h}$ - aluminum
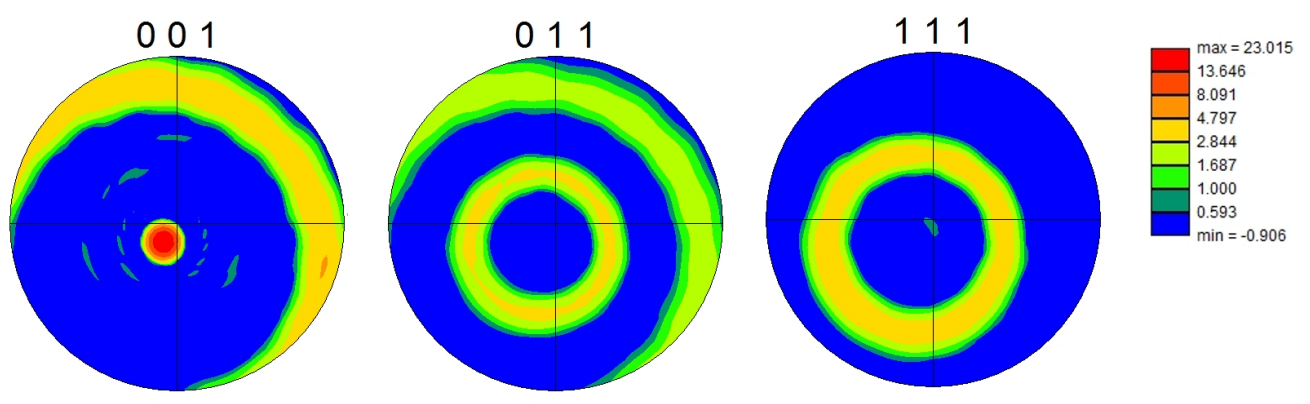

(c) ACCA $1 \mathrm{~mm} 400^{\circ} \mathrm{C}-6 \mathrm{~h}$ - copper
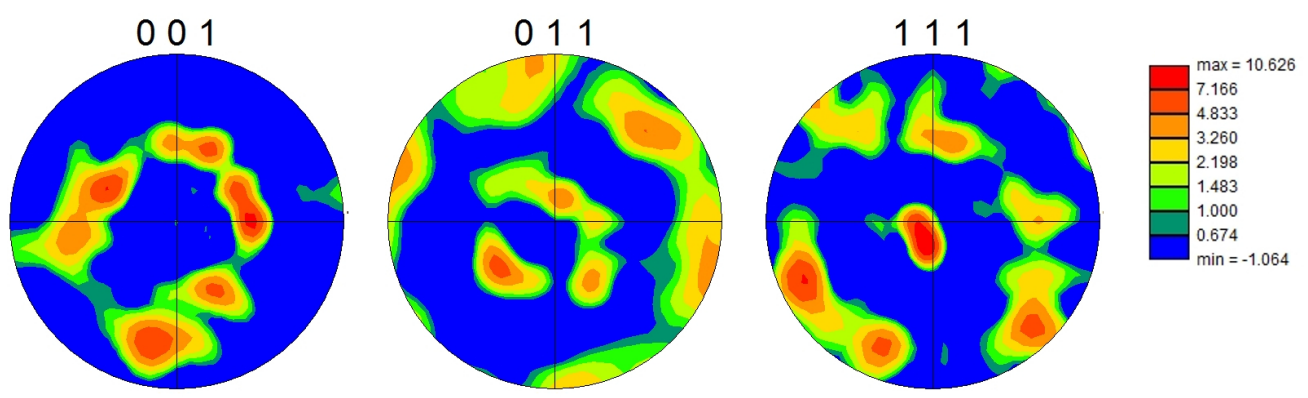

(d) $\mathrm{ACCA} 1 \mathrm{~mm} 400^{\circ} \mathrm{C}-6 \mathrm{~h}$ - aluminum

Figure 5: Pole figures associated to the cross section of the architectured $\mathrm{Cu}-\mathrm{Al}$ composite wires, heat treated at $400^{\circ} \mathrm{C}$ for $6 \mathrm{~h}$ with the following diameters: (a) $3 \mathrm{~mm}$ diameter - $\mathrm{Cu}$, (b) $3 \mathrm{~mm}$ diameter - $\mathrm{Al}$, (c) $1 \mathrm{~mm}$ diameter - $\mathrm{Cu}$ and (d) $1 \mathrm{~mm}$ diameter - Al. 
Table 1 summarizes the following characteristics of each ACCA sample: final diameter, average plastic strain during the process (estimated from eq.1), Grain Size (GS) of the $\mathrm{Cu}$ and $\mathrm{Al}$ phases, alongside their corresponding maximal density pole (indicating the texture intensity, I). The volume fractions $\left(f_{w}\right)$ of $\mathrm{Al}, \mathrm{Cu}, \mathrm{Al}_{4} \mathrm{Cu}_{9}, \mathrm{AlCu}$ and $\mathrm{Al}_{2} \mathrm{Cu}$ are also estimated using the average aluminum area and the growth kinetics of the intermetallic compounds reported in previously published papers for the same materials $[14,16]$. The same microstructural characteristics for the conventional CCA wires are also included in this table.

Table 1: Microstructural characteristics of all investigated architectured and non-architectured Cu-Al samples including grain size (GS expressed in $\mu \mathrm{m})$, maximal density pole (I, expressed in Multiple Ramdom Distribution - M.R.D.), and the volume fraction $\left(f_{w}\right)$ of each phase. AD (As-Drawn), $\mathrm{HT} 1\left(400^{\circ} \mathrm{C}-30 \mathrm{~min}\right)$ and $\mathrm{HT} 2\left(400^{\circ} \mathrm{C}-6 \mathrm{~h}\right)$, represent the heat treatment conditions considered after processing.

\begin{tabular}{|c|c|c|c|c|c|c|c|c|c|c|c|}
\hline \multirow{3}{*}{$\begin{array}{c}\text { Sample } \\
\text { type }\end{array}$} & \multirow{3}{*}{$\begin{array}{l}\text { Plastic } \\
\text { strain }\end{array}$} & \multirow{3}{*}{ State } & \multicolumn{9}{|c|}{ Phases } \\
\hline & & & \multicolumn{3}{|c|}{$\mathrm{Cu}$} & \multicolumn{3}{|c|}{$\mathrm{Al}$} & \multirow{2}{*}{$\begin{array}{c}\mathrm{Al}_{4} \mathrm{Cu}_{9} \\
f_{w}\end{array}$} & \multirow{2}{*}{$\begin{array}{c}\mathrm{AlCu} \\
f_{w} \\
\end{array}$} & \multirow{2}{*}{$\begin{array}{c}\mathrm{Al}_{2} \mathrm{Cu} \\
f_{w} \\
\end{array}$} \\
\hline & & & GS & I & $f_{w}$ & GS & I & $f_{w}$ & & & \\
\hline & & $\mathrm{AD}$ & 0.4 & 23 & 0.74 & 0.4 & 21 & 0.26 & & No IMCs & \\
\hline \multirow[t]{3}{*}{ ACCA $1 \mathrm{~mm}$} & 9.5 & HT1 & 4 & 18 & 0.67 & 6 & 15 & 0.23 & 0.032 & 0.015 & 0.053 \\
\hline & & HT2 & 7 & 23 & 0.57 & 10 & 10 & 0.16 & 0.115 & 0.040 & 0.115 \\
\hline & & $\mathrm{AD}$ & 0.5 & 25 & 0.74 & 0.4 & 20 & 0.26 & & No IMCs & \\
\hline \multirow[t]{3}{*}{ ACCA $1.7 \mathrm{~mm}$} & 8.56 & HT1 & 7 & 11 & 0.72 & 10 & 14 & 0.22 & 0.017 & 0.01 & 0.030 \\
\hline & & HT2 & 11 & 9.5 & 0.68 & 60 & 9 & 0.17 & 0.06 & 0.02 & 0.07 \\
\hline & & $\mathrm{AD}$ & 0.4 & 20 & 0.74 & 0.3 & 18 & 0.26 & & No IMCs & \\
\hline \multirow[t]{3}{*}{ ACCA 3 mm } & 7.37 & HT1 & 5 & 26 & 0.73 & 4.5 & 5.8 & 0.24 & 0.01 & 0.005 & 0.017 \\
\hline & & HT2 & 40 & 6.3 & 0.69 & 80 & 14 & 0.22 & 0.03 & 0.015 & 0.04 \\
\hline & & $\mathrm{AD}$ & 5 & 16 & 0.49 & 1 & 16 & 0.51 & & No IMCs & \\
\hline \multirow[t]{2}{*}{ CCA $1 \mathrm{~mm}$} & 4.97 & HT1 & 7 & 18 & 0.485 & 5 & 15 & 0.498 & 0.005 & 0.005 & 0.01 \\
\hline & & HT2 & 10 & 15 & 0.47 & 8 & 12 & 0.49 & 0.017 & 0.0065 & 0.02 \\
\hline
\end{tabular}




\subsection{Tensile tests}

Figures 6(a), 6(b) and 6(c) show the engineering tensile curves for the AD, HT1 and HT2 ACCA wires respectively. Tensile curves of the conventional $1 \mathrm{~mm}$-diameter CCA wires, with the same heat treatment conditions, are also included in the figures for comparison purposes.

For the as-drawn samples (fig. 6(a)), the yield stress for three different diameters is very similar during the tensile test. This result can be attributed to the dynamic recovery occurring in both phases during the process, leading to similar grain size and texture (see table 1). The ductility of both ACCA and CCA wires is generally low (average fracture strain about 0.01). The ACCA wires, however, exhibit larger yield stress compared to CCA ones, probably due to the larger volume fraction of copper in the architectured samples and their lower grain size.

For the HT1 conditions (fig. 6(b)), the tensile behavior is strongly dependent on the wire diameter. The yield stress increases from $100 \mathrm{MPa}$ to $180 \mathrm{MPa}$ with a decrease in diameter from 3 to $1 \mathrm{~mm}$. The yield stress of the $1 \mathrm{~mm}$-diameter architectured wires is $80 \mathrm{MPa}$ higher than the value for a conventional $1 \mathrm{~mm}$-diameter CCA wires. The recrystallization occuring during the heat treatment clearly enhances ductility with an increase in plastic strain at fracture, for instance, from 0.01 (as-drawn) to 0.2 (HT1) for the $3 \mathrm{~mm}$ diameter. Nevertheless, the plastic strain at failure strongly depends on the wire diameter. Similar trends are observed for the HT2 sample (fig. 6(c)). An analogy between the HT1 and HT2 yield stress values reveals that, for a given wire diameter, longer heat treatments lead to higher yield stresses. The smallest-diameter HT2 sample exhibits brittle behavior, probably due to the larger volume fraction of IMCs, as reported in table 1. An unexpected plateau of almost constant stress can be seen beyond the elastic domain on the stress-strain curve of the two sets of heat-treated samples (HT1 and HT2). A number of serrations are also observed along the plateau, as depicted in the figure 6(c).

Figure 7 illustrates the strain hardening rate as a function of strain, for the heat treated samples. It can be observed from this figure that the strain hardening rate evolution $(\theta)$ can be divided into four different stages. The first one, characterized by a strong decrease in $\theta$, appears at strains lower than 0.01 and can be ascribed to the gradual generalization of plasticity within the material $[25,26]$. This plasticity generalization is expected to occur gradually between the two phases due to their differing Youngs modulus and yield stress values (typically around $400 \mathrm{MPa}$ of as-drawn $\mathrm{Cu}[27,28]$ and $200 \mathrm{MPa}$ for as-drawn Al [29]). Moreover, due to the different grain orientations in each phase, a plasticity generalization is also expected from the well-oriented grains (with respect to the tensile axis) to the poor oriented ones. Then, the unexpected plateau of low hardening rate appears in the stage I'. The strain range at this stage depends on the wire diameter, duration of heat treatment and seemingly the IMC volume fraction. 


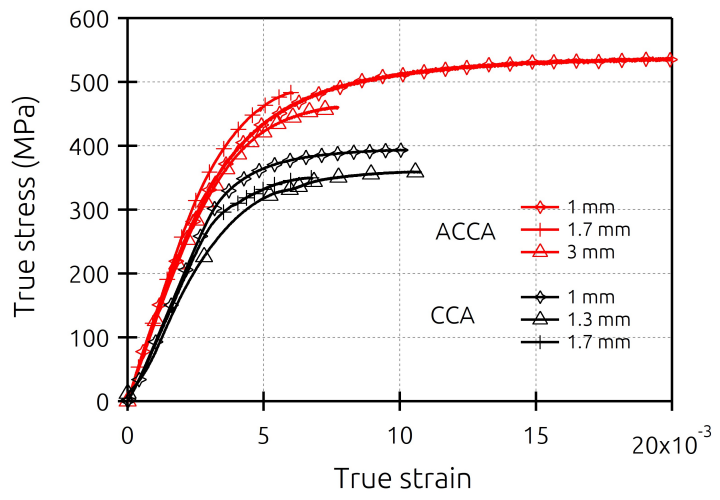

(a) As-drawn

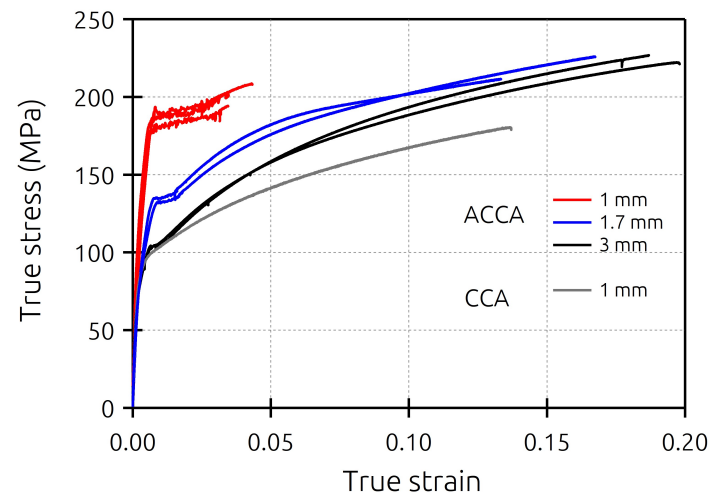

(b) $400^{\circ} \mathrm{C} 30 \mathrm{~min}$

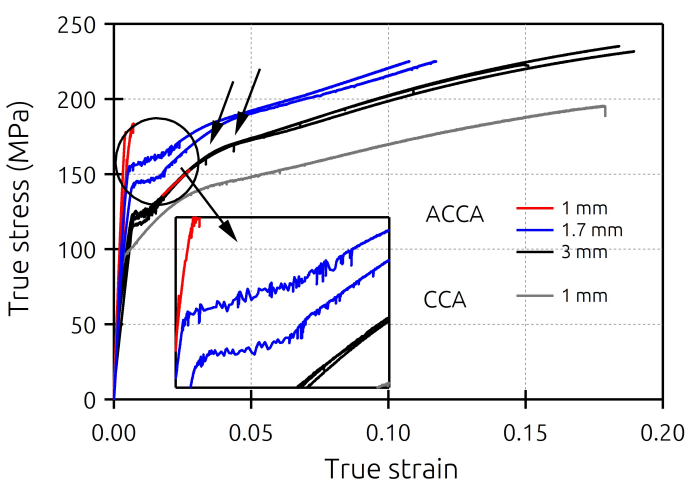

(c) $400^{\circ} \mathrm{C} 6 \mathrm{~h}$

Figure 6: Engineering tensile curves of the architectured copper-aluminum composites: (a) as-drawn (AD), (b) heat-treated at $400{ }^{\circ} \mathrm{C}$ for 30 min (HT1) and (c) heat-treated at $400{ }^{\circ} \mathrm{C}$ for $6 \mathrm{~h}(\mathrm{HT} 2)$. 
The stage II begins as the plateau fades away. Here, the curve exhibits $\theta$ values around $2000 \mathrm{MPa}$, the same as the strain hardening rates reported for large-grain pure copper [30] and aluminum [31]. Following a short transition, the stage III, with an almost constant $\theta$ value, extends up to fracture. Furthermore, this stage begins at lower strain values for HT2 compared to HT1. All the above-mentioned stages, including the transition (labelled trans.) between stage II and stage III, are designated in figure 7(b) for the HT2 3 mm-diameter wire.

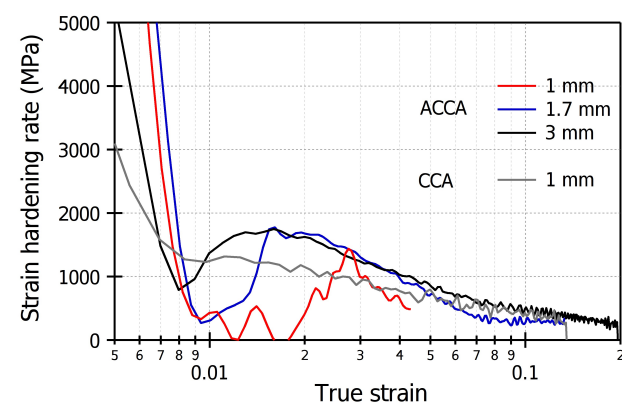

(a) $400^{\circ} \mathrm{C} 30 \mathrm{~min}$

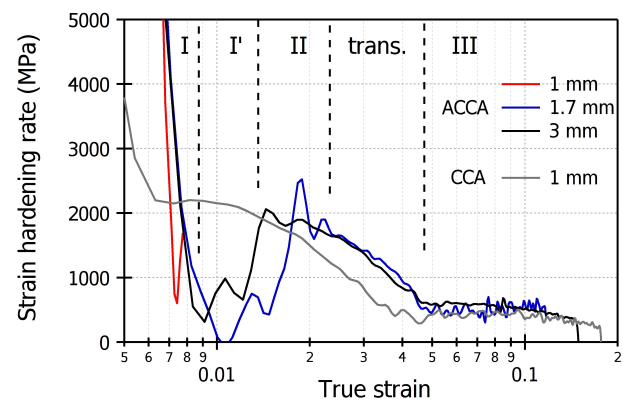

(b) $400^{\circ} \mathrm{C} 6 \mathrm{~h}$

Figure 7: Evolution of the strain hardening rate versus strain for the following copper-aluminum composites: heat treated at $400^{\circ} \mathrm{C}$ (a) for $30 \mathrm{~min}$ and (b) for $6 \mathrm{~h}$.

\subsection{Nanohardness}

Nanoindentation tests were carried out in order to examine the effect of the sample characteristics (architecture, wire diameter and heat treatment) on the mechanical behavior of each phase. To this end, the cross-sections of 1 $\mathrm{mm}$ and $3 \mathrm{~mm}$-diameter samples of CCA and ACCA in the as-drawn and HT2 states were analyzed. Modulus and hardness profiles across the $\mathrm{Cu} / \mathrm{Al}$ and $\mathrm{Cu} / \mathrm{IMC} / \mathrm{Al}$ interfaces were acquired for all samples. Figure 8 represents the aforesaid type of profile for the HT2 3-mm diameter ACCA sample. Two intermetallic compounds named IMC1 and IMC2 with modulus values of about 90 and 130 GPa respectively, can be observed in this figure in agreement with the previous works on CCA [15]. It can be concluded from the literature [32, 33], that IMC1 and IMC2 are related to $\mathrm{Al}_{2} \mathrm{Cu}$ and $\mathrm{AlCu}$ in the order given. The hardness is almost the same for both IMCs with values around $9 \mathrm{GPa}$, being also consistent with the literature [21].

Using the above-mentioned profiles, average values of hardness and modulus for $\mathrm{Cu}$ and $\mathrm{Al}$ are calculated for each sample and a summary of the results is presented in table 2. The experimental values and their corresponding experimental uncertainty values are reported with a confidence level of $95 \%$. 


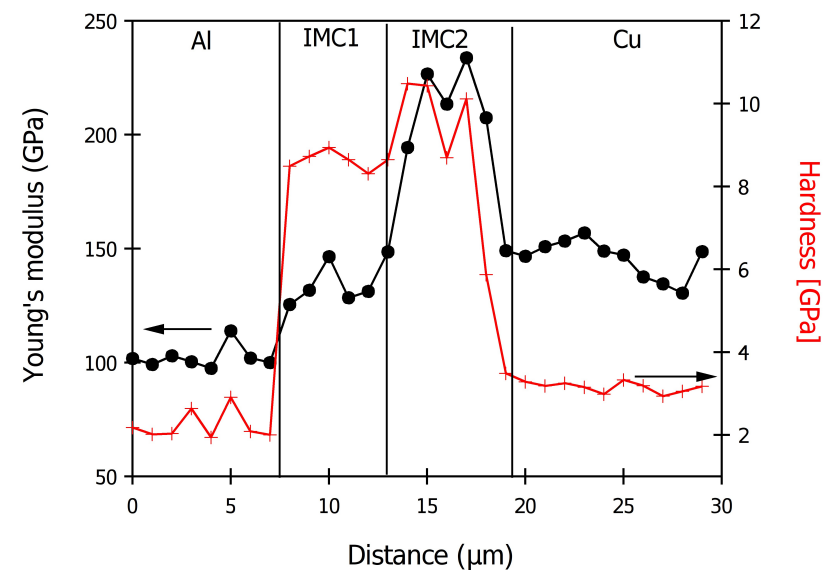

Figure 8: Modulus and hardness profile for a $3 \mathrm{~mm}$ diameter architectured copper-aluminum composite obtained by cold-drawing via restacking method after the $400{ }^{\circ} \mathrm{C} 6 \mathrm{~h}$ heat treatment. 


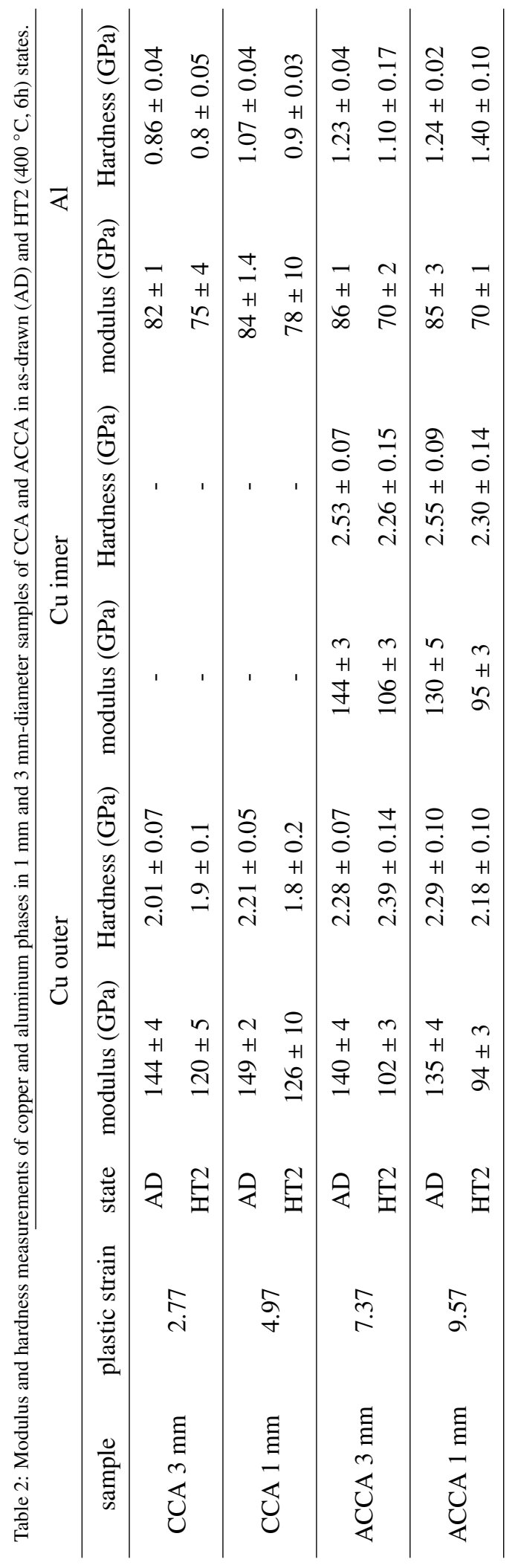


Taking into account the dispersion of the experimental modulus values in the as-drawn state, the sample characteristics show almost no impact on this parameter revealing no phase transformation or damage as a result of the process. Regarding the ACCA wires, the copper hardness is lower at the outer surface than in the inner part. This feature is probably due to the larger plastic strain sustained by the restacked CCA wires throughout the process. A comparison between the hardness values of $\mathrm{Al}$ and $\mathrm{Cu}$ in the architectured and non-architectured samples shows that the ACCA wires exhibit higher hardness values that could be attributed to the higher plastic deformation undergone during wire manufacturing.

In the HT2 heat-treated conditions, no statistically significant differences in hardness and module appear between the 1 and $3 \mathrm{~mm}$ diameter samples due to the sample recrystallization. A comparison between the aluminum and copper hardness values in the as-drawn and heat-treated states shows insignificant variations. However, for the two investigated sample diameters, the heat treatment leads to a decrease in modulus for $\mathrm{Al}$ and $\mathrm{Cu}$ phases, probably due to the texture evolution during the HT. This decrease is larger for copper than for aluminum. Regardless of the samples heat treatment condition and diameter, it is worth noticing that the average ratio of $\mathrm{Al}$ hardness to $\mathrm{Cu}$ for the ACCA samples is about 0.5 indicating the occurrence of a similar hardening mechanism in each phase.

\subsection{Fracture surfaces}

Figures 9(a) and 9(b) illustrate the fracture surfaces of two $1 \mathrm{~mm}$-diameter ACCA specimens, the former in the as-drawn and the latter in HT1 state (the results are similar for the other diameters and the second heat treatment condition). In the as-drawn state, a transgranular ductile fracture of $\mathrm{Al}$ and $\mathrm{Cu}$ can be observed in figure 9(a). Contrary to $\mathrm{Al}$, where larges dimples can be seen, no dimples are observed in the copper phase. Moreover, this figure reveals that fracture at the $\mathrm{Cu}-\mathrm{Cu}$ interface between the re-stacked wires occurs, most probably due to a weak mechanical bonding during the process [3]. Post-heat treatment Al fracture surface (figure 9(b)) shows no modification of the fracture mechanism. This figure is, furthermore, indicative of better bonding built at the $\mathrm{Cu}-\mathrm{Cu}$ interface of the restacked wires. Few dimples appear across the interface, presumably because of the superficial contaminants resting across the copper wires during the process as reported in [16]. The IMC layer cracks perpendicularly to the tensile direction (perpendicular to the image plane) as expected and indicated in figure 9(b). This figure also shows several IMC/IMC and Al/IMC cracks, developed locally.

Those IMC and IMC/metal crack formations are confirmed by the longitudinal section observation, below the fracture surface, illustrated in figure 9(c). At fracture, all IMCs layers are regularly broken into parts of about $30 \mu \mathrm{m}$. $\mathrm{IMC} / \mathrm{Al}$ cracks are frequently observed contrarily to $\mathrm{IMC} / \mathrm{Cu}$ which are not observed revealing the higher strength of the $\mathrm{Cu}-\mathrm{IMC}$ bonding compared to the IMC-Al one. 


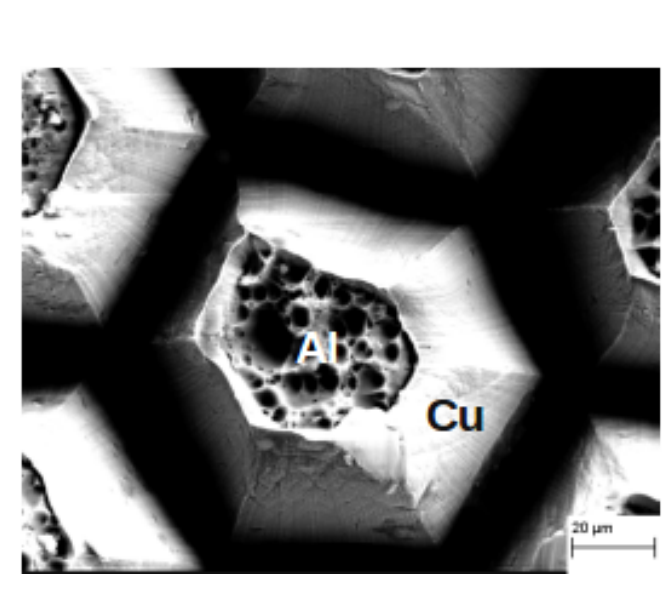

(a) as-drawn - $1 \mathrm{~mm}$ diameter

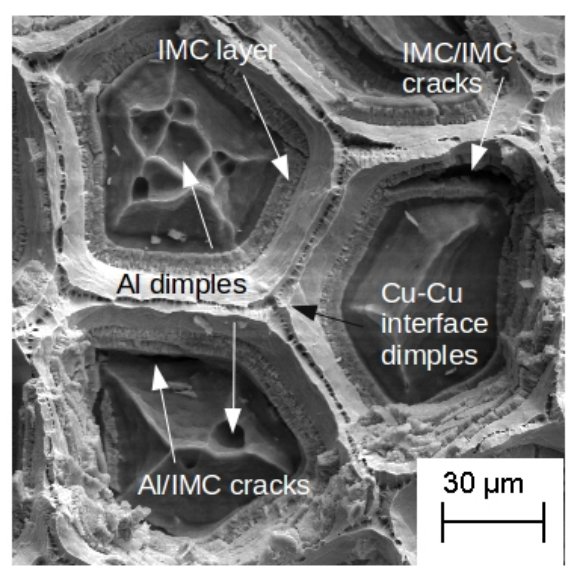

(b) $400^{\circ} \mathrm{C} 30 \mathrm{~min}-1 \mathrm{~mm}$ diameter

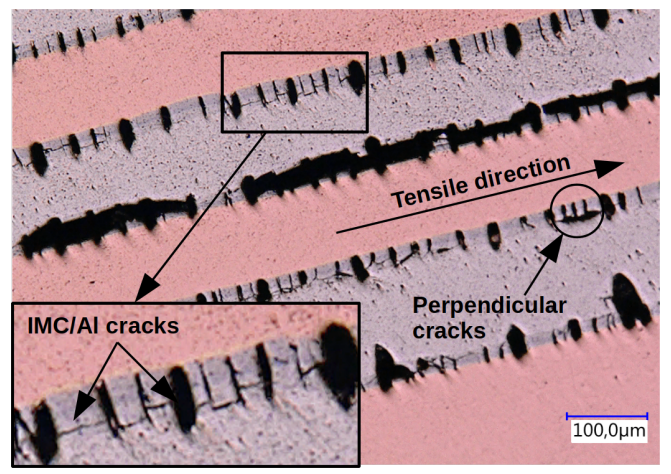

(c) $400^{\circ} \mathrm{C} 6 \mathrm{~h}-3 \mathrm{~mm}$ diameter

Figure 9: Microstructure observation at fracture for architectured $\mathrm{Cu}-\mathrm{Al}$ composites: (a) fracture surface for a $1 \mathrm{mm-diameter}$ wire in as-drawn conditions, (b) fracture surface for a $1 \mathrm{~mm}$-diameter wire heat treated at $400^{\circ} \mathrm{C}$ for $30 \mathrm{~min}$ and (c) longitudinal section for a $3 \mathrm{~mm}$-diameter wire heat treated at $400^{\circ} \mathrm{C}$ for $6 \mathrm{~h}$.

\section{Discussion}

The results presented above show the influence of architecture and heat treatments on the strain and fracture mechanisms of the architectured $\mathrm{Cu}-\mathrm{Al}$ composites. These results are discussed in terms of the architecture, intermetallic compounds volume fraction and grain size in the following paragraphs.

\subsection{Effect of the manufacture process on the microstructure}

Taking into account the microstructural analysis reported in section 3.1, the grain size and texture of the as-drawn ACCA samples do not seem to be dependent on the wire diameter. Submicrometer grains are observed in $\mathrm{Cu}$ and Al for all as-drawn ACCA samples with the crystallographic directions of $<111>$ and $<001>$ as major and minor components of the texture, respectively. These results suggest the occurrence of dynamic recovery throughout the process, leading to an almost steady microstructural state. For the CCA specimens, the grain size is larger than ACCA 
ones due to the lower plastic strain associated with the process. Additionally, the texture of the $\mathrm{Al}$ and $\mathrm{Cu}$ phases of the CCA and ACCA wires are similar to those of the drawn pure FCC metals, suggesting that the strain distribution pattern brought about by the process (which influence the texture formation), does not vary in the cold drawn $\mathrm{Cu}-\mathrm{Al}$ composites.

The volume fraction of the IMCs in the heat-treated samples depends on the final diameter of the wire and the heat treatment conditions, varying between $0.03\left(3 \mathrm{~mm}\right.$ diameter $\left.-400{ }^{\circ} \mathrm{C} 30 \mathrm{~min}\right)$ and $0.26\left(1 \mathrm{~mm}\right.$ diameter $-400{ }^{\circ} \mathrm{C}$ 6h). $\mathrm{Al}_{2} \mathrm{Cu}$ has the largest volume fraction among the IMCs in all the samples. However, predominance of $\mathrm{Al}_{2} \mathrm{Cu}$ is in contradiction with the observations reported by Kim and coworker [23] for $\mathrm{Cu} / \mathrm{Al} / \mathrm{Cu}$ trilayers obtained by RollBonding (RB) which exhibit a larger volume fraction of $\mathrm{Al}_{4} \mathrm{Cu}_{9}$.

The effect of processing on the heat treated samples, in terms of grain size and texture, depends on the material. As expected, an increment in the grain size of copper, for a given diameter following longer heat-treatments, is observed. The grain size is also affected by the wire diameter for a given heat treatment since recrystallization is dependent on the accumulated strain energy during the process. Figure 5(a) and figure 5(c) show that texture still exists in the copper phase of the heat treated samples after recrystallization. Moreover, the texture components and intensities depend on the heat treatment duration and wire diameter. Table 3 summarizes, for $\mathrm{Cu}$ and $\mathrm{Al}$, the grain volume fraction with $<111>,<001>$ and $<110>$ crystal orientation along the tensile axis, for the different samples characterized in this study.

For the shorter heat treatments (HT1), the $<001>$ fiber component prevails over the $<111>$, independently on the wire diameter. Park and Lee [18] suggested that the aforementioned increase in the volume fraction of the $<001>$ fiber component indicates that only primary recrystallization, controlled by the stored strain energy, takes place in copper. In this case, the maximal density pole associated with the texture is still high.

For longer-duration heat treatments, the ACCA samples with $1.7 \mathrm{~mm}$ and $3 \mathrm{~mm}$ diameter exhibit a slighlty higher volume fraction of $<111>$ oriented grains compared to the $<001>$. The occurrence of primary and secondary recrystallization (controlled by grain growth) in these two samples leads to a reduced texture intensity [18]. As observed in figure 3(b), during this secondary recrystallization, grain growth for copper is more pronounced in $<111>$ oriented grains compared to the $<001>$, in agreement with previous work published on Ag wires [34]. As a result the $<111>$ component volume fraction increases according to table 3 . For the $1 \mathrm{~mm}$ diameter sample in the HT2 conditions, no further texture evolution compared to shorter heat treatment is characterized, revealing that secondary recrystallization did not occur for this sample due to the high plastic strain involved during the process.

The post-heat-treatment aluminum grain orientations are similar to those already reported for the cold-drawn wires 
$[35,36]$. Both primary and secondary recrystallization take place within shorter heat-treatment periods in this material due to the lower homologous temperature of aluminum compared to copper. Subsequently, figure 3(c) shows the majority of grains orientated towards $<111>$ along the wire axis. Park and Lee [18] concluded that the volume fraction of $<111>$ increases by extending the heat treatment duration, prompting a rise in the maximal density pole value, as already reported for aluminum alloys processed by multi directional forging [37]. 


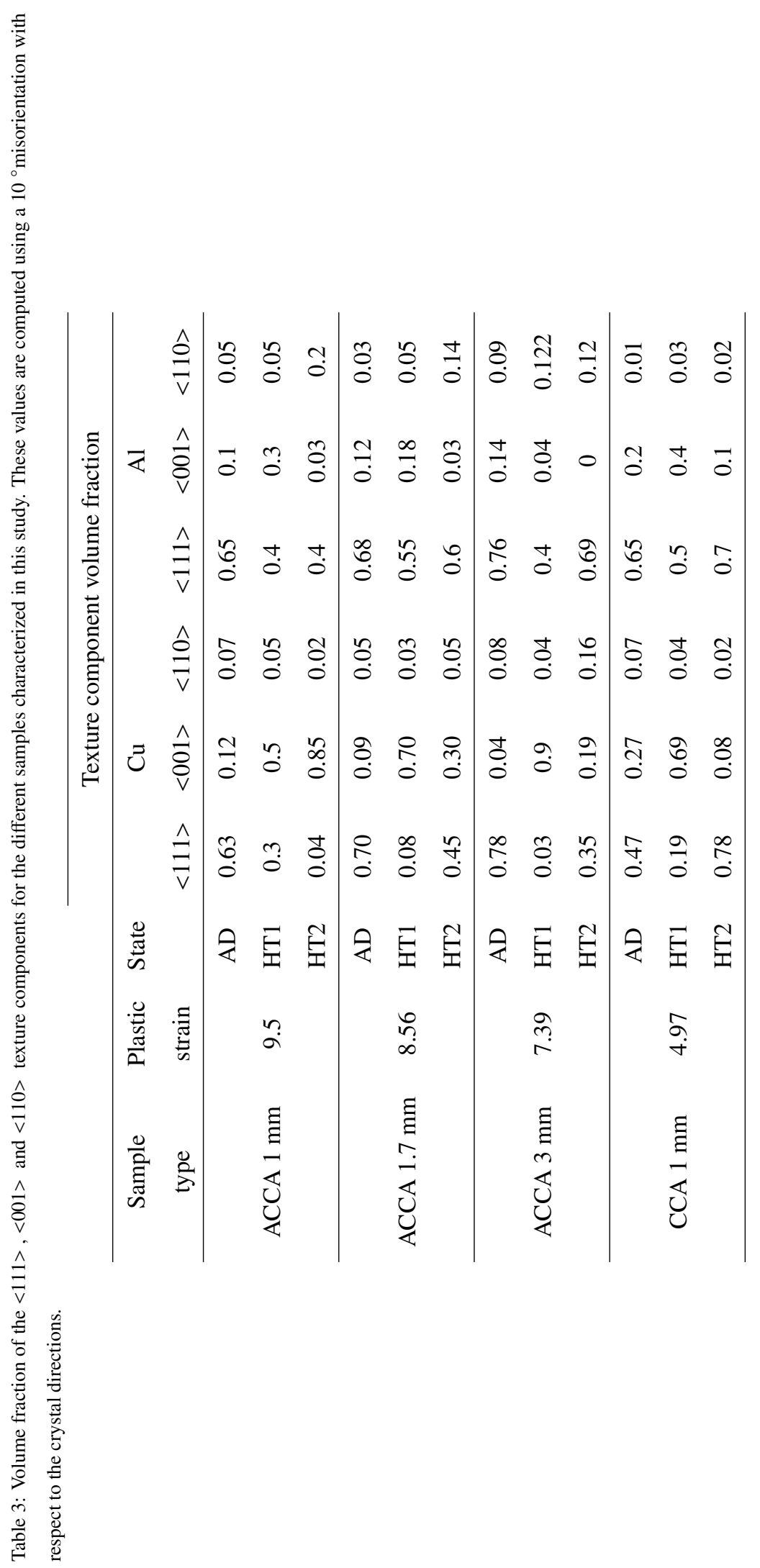




\subsection{Effect of the architecture on the mechanical behavior of the as-drawn samples}

Figure 6(a) demonstrates a difference between the yield stress values of the conventional and architectured $\mathrm{Cu}-\mathrm{Al}$ composites in the as-drawn state. Because of the significant dynamic recovery that takes place in both $\mathrm{Cu}$ and $\mathrm{Al}$ during processing, the wire diameter seems to have little impact on the yield stress of either architectured or nonarchitectured samples. These results are consistent with those reported for pure copper samples manufactured by wire drawing and accumulative roll bonding, for which the flow stress depends on the process plastic strain only trivially if this parameter is larger than 2 [20]. Assuming that a conventional rule of mixture can be employed for the CCA and ACCA samples for which there is no size effect involved (large characteristic dimensions for the copper and aluminum path), the average experimental yield stress for CCA and ACCA can be compared, as a first approximation, to the predictions of the Voigt (upper bound - linear relationship) and Reuss (lower bound - inverse relationship) boundaries of the rule of mixture. To this end, the mechanical behavior of copper and aluminum in tension were separately investigated with the same test configuration for the composite wires. The pure $\mathrm{Cu}$ and $\mathrm{Al}$ samples (same material as for the composite wires) were fabricated under the same conditions as the CCA and ACCA specimens to have the different degrees of plastic strain undergone by CCA and ACCA wires into consideration.

In order to achieve this aim, $1 \mathrm{~mm}$-copper-copper wires were first obtained from cold drawing of a copper tube and a copper rod of the same dimensions of the $\mathrm{Cu}$ and $\mathrm{Al}$ counterparts used for manufacturing the $\mathrm{CCA}$ sample. For this pure $1 \mathrm{~mm}$ diameter $\mathrm{Cu}$ wire similar to CCA, the yield stress is about $380 \mathrm{MPa}$. 61 of these all-copper wires were then restacked into a copper tube and further cold-drawn to a diameter of $1 \mathrm{~mm}$ to ensure reaching the same strain level as the $1 \mathrm{~mm}$-ACCA sample (i.e $\eta=9.5$ ). The yield stress of this full-copper ACCA counterpart is about $410 \mathrm{MPa}$ in agreement with the $380 \mathrm{MPa}$ saturation stress reported in previous works for strains up to 10 [27, 28]. An aluminum rod and an aluminum tube of the same dimensions of those employed to fabricate the ACCA samples were first cold-drawn to $1 \mathrm{~mm}(\eta=2.5)$. The yield stress of the full-aluminum CCA counterpart is about $197 \mathrm{MPa}$. Further drawing of these wires, when restacked into an annealed aluminum tube, was unsuccessful due to the large hardness contrast between them. Assuming the ratio of the yield stress of aluminum to that of copper to be similar for CCA and ACCA (as observed for the nanohardness values - see table 2), the yield stress of full pure aluminum-ACCA counterpart is expected to be about $210 \mathrm{MPa}$.

Using these values of yield stress for $\mathrm{Cu}$ and $\mathrm{Al}$, and considering a pure plastic perfect behavior (associated with the dynamic recovery during the process), the upper and lower boundaries for the theoretical rule of mixtures are plotted for the yield stress in figure 10, as a function of the aluminum volume fraction for CCA and ACCA wires. The average experimental values for the CCA $(51 \%$ of $\mathrm{Al})$ and ACCA (26\% of $\mathrm{Al})$ are also indicated for comparison purposes. 


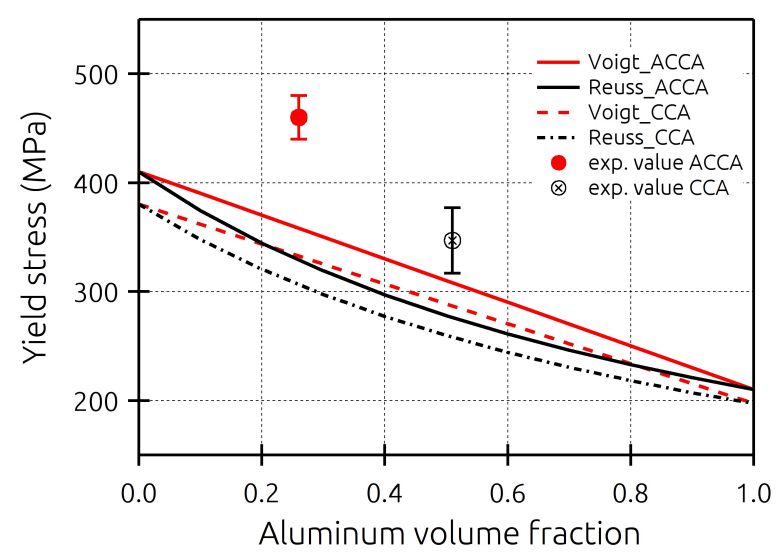

Figure 10: Comparison between the Voigt and Reuss prediction for the yield stress of $\mathrm{Cu}-\mathrm{Al}$ composites.

The prediction of the rule of mixture is $50 \mathrm{MPa}$ lower than the experimental yield stress value for the CCA sample, demonstrating some potentially weak extra hardening because of the two phases involved and their corresponding interfaces. The yield strength of the ACCA sample, however, shows a positive $100 \mathrm{MPa}$ deviation from the prediction of the rule of mixtures and is additionally higher than the yield stress of the full-copper ACCA counterpart. For $\mathrm{Cu} / \mathrm{Al} / \mathrm{Cu}$ trilayers obtained by RB, an opposite trend was reported for the ultimate tensile strength which is slighly lower than the value predicted by the linear rule of mixtures [23]. A clear hardening effect of the composite architecture is then characterized.

In the as-drawn state, the dominant $<111>$ crystal direction alongside the wire axis exhibits the highest Young's modulus difference between $\mathrm{Cu}$ and $\mathrm{Al}$. Using the values reported in the literature [38], obtained from the compliance matrix for the $<111>$ orientation, the elastic modulus of copper and aluminum are 191 and $76 \mathrm{GPa}$, in that order. The coupled effect of this difference in elastic properties and yield strength results in residual stresses induced during the process [39, 40, 41]. Following the analytical computations by Bullough and Hartley [41] of residual stress in a 50\%-Al CCA wire strained up to 4 (equivalent to a $1 \mathrm{~mm}$-diameter CCA wire in this study), axial compressive stresses of about $80 \mathrm{MPa}$ are expected in aluminum, whereas there would be around $70 \mathrm{MPa}$ of tensile stress in copper. Tensile residual stresses in copper, however, decrease for lower volume fractions of aluminum and increases at higher plastic strains. Low Al volume fraction and large processing strains lead to a higher level of compressive stresses in the aluminum component of the ACCA samples compared to the CCA samples. The stress level leading to plastic flow in the aluminum phase is then higher in the ACCA sample compared to the CCA sample, which in part explains the wider gap between the experimental yield stress and the Voigt prediction. 
Furthermore, at the onset of plasticity in copper (which deforms plastically first), strong plastic strain incompatibilities will appear between this phase and aluminum (which still behaves elastically). This strain incompatibilities may enhance the formation of strong backstresses and geometrically necessary dislocations in copper phase near the interfaces between the two phases. As the interface density by volume unit is larger for the ACCA compared to CCA, this phenomenon may also explain the extra-hardening of the architectured composite characterized in this study. An extensive investigation of the role played by the architecture on the process induced residual stresses and the influence of the interface must be performed to better understand the origin of this such elevated yield stresses.

\subsection{Influence of the heat-treatments on the mechanical properties of the Cu-Al composites}

Figures 6(b) and figure 6(c) clearly show the effect of the volume fraction of the intermetallic compounds on the tensile curves. To make comparisons between the IMCs effect on the mechanical behavior of the samples with different heat treatment conditions, the yield stress and Ultimate Tensile Strength (UTS) as a function of IMC volume fraction in HT1 and HT2 conditions are plotted in figure 11. For the same volume fraction of IMCs, the yield stress of the sample heat treated at $400^{\circ} \mathrm{C}$ for 30 minutes, is significantly larger than the one heat treated at $400{ }^{\circ} \mathrm{C}$ for six hours. As summarized in table 1, the grain size of the HT2 sample is larger than the HT1 one. In agreement with those results, the grain size strengthening is then lower for HT2 than for HT1. Moreover, the difference in Schmid factor between each texture component $(0.401$ for a theoretical $<001>$ versus 0.27 for $<111>$ one) can impact the yield stress, depending on the type of the recrystallization (primary or secondary) occurring during the heat-treatment. The yield stress of the ACCA wires is then a function of the heat treatment-dependent characteristics such as the volume fraction of IMCs, grain size and texture.

Regardless of the grain size, larger volume fractions of IMCs decrease the UTS as a result of early fracture. Such early fracture, happening in the samples with larger volume fractions of IMCs, may result from the large tensile stresses undergone by the brittle compounds but also from the weak metal/IMC interface in the samples with large IMC thicknesses, according to the literature [2, 3].

The volume fraction of IMCs also affects the strain hardening stages of the architectured $\mathrm{Cu}-\mathrm{Al}$ composites. Firstly, the occurrence of the stage I' with no or weak hardening is clearly related to the IMCs as no static strain ageing is expected for this material. This stage is connected with the serrated flow, observed on the stress-strain curve, similar to those observed during dynamic strain aging (see figure 6(c) inset). In some cases, these serrated parts are observed for larger plastic strains (see black arrows in figure 6(c)) and have been also reported by Kocich and coworkers for $\mathrm{Cu} / \mathrm{Al} / \mathrm{Cu}$ trilayers [12]. These authors incriminated the propagation of shear bands within the metallic composites. However, since the oscillations primarily appear at the onset of plasticity in the samples with different volume fractions of IMCs, the gradual fracture of the intermetallic compounds which cannot bear rather high tensile 


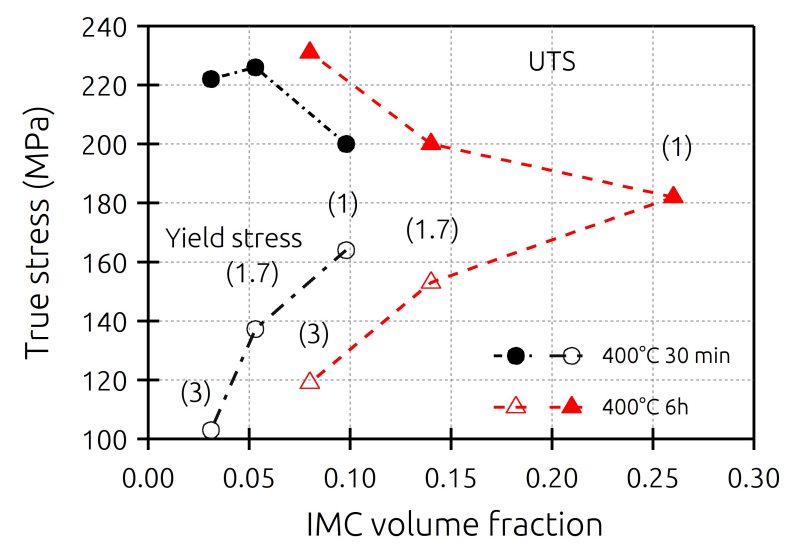

Figure 11: Evolution of the yield stress and Ultimate Tensile Strength (UTS) as a function of the volume fraction of the intermetallic compounds. Wire diameter is indicated between brackets for yield stress.

strains (see figure 9(c)), is believed to cause the stage I' to appear.

Second of all, the stage III, with a constant strain hardening rate of around $800 \mathrm{MPa}$, reveals that dislocation annihilation processes (which generally act in pure copper and aluminum) may be counterbalanced by a dislocation generation mechanism. The dimples observed on the fracture surface of the copper network in the HT1 sample are typical of its larger stress triaxiality compared to as-drawn samples [42]. This may result from a change in the stress state within copper and aluminum phases because of the radial deformation restriction imposed by the IMCs (only few interfacial cracks observed in figure 9). Moreover, according to the litterature [43], stress concentration in $\mathrm{Al}$ and $\mathrm{Cu}$ phases can occur at large plastic strains, as a result of fracture in IMCs. The stress concentration points suggests that dislocation generation probably counterbalances the dislocation annihilation mechanism by cross-slip. 


\section{Conclusions}

In this study, architectured $\mathrm{Cu}-\mathrm{Al}$ composite wires were manufactured via cold drawing applying a restacking method. The mechanical properties of the wires, including hardness and tensile behavior, were examined, under the following heat treatment conditions: as-drawn, $400{ }^{\circ} \mathrm{C}-30 \mathrm{~min}$ and $400{ }^{\circ} \mathrm{C}-6 \mathrm{~h}$. The conclusions made are listed below:

- The microstructure, in terms of grain size, texture, IMC type and its volume fraction strongly depends on the manufacturing conditions;

- in the as-drawn state, the improvement of the mechanical properties for ACCA, partly coming from the larger volume fraction of copper, highlights the important role played by the architecture, the difference between the elastic modulus of $\mathrm{Cu}$ and $\mathrm{Al}$ and the density of the $\mathrm{Cu} / \mathrm{Al}$ interface.

- a comparison between the as-drawn and heat-treated samples shows that the two heat treatments lead to a reduction in the yield stress and an increase in the ductility, if the IMC volume fraction remains low, because of the recrystallisation of both $\mathrm{Al}$ and $\mathrm{Cu}$ phases. The recrystallization is also responsible for heat-treatment dependence of texture components;

- the volume fraction of the intermetallics significantly influences the yield stress, fracture strain and strainhardening mechanisms, by inducing new stages on the strain-hardening curves, compared to those of the conventional pure copper and aluminum.

The architectured composite wires, with low intermetallic volume fractions, exhibit slightly improved mechanical properties, compared to those of conventional copper-clad aluminum wires. Considering the good electrical conductivity of those architectured wires, they could be considered as innovative alternatives to the conventional copper-clad aluminum wires, for carrying electric currents over an even wider range of frequencies. An ongoing study is already carried out to better understand how both the architecture and intermetallics influence the mechanical properties of $\mathrm{Cu}-\mathrm{Al}$ composite wires.

\section{Acknowledgment}

The authors acknowledge the financial support of the the Condulight project by the Carnot ESP institution. Mayerling Martinez is also aknowledged for the ASTAR TEM characterization. 


\section{Data availability}

The raw/processed data required to reproduce these findings cannot be shared at this time as the data also forms part of an ongoing study

\section{References}

[1] M. R. Toroghinejad, R. Jamaati, J. Dutkiewicz, J. A. Szpunar, Investigation of nanostructured aluminum/copper composite produced by accumulative roll bonding and folding process, Materials and Design 51 (2013) $274-279$.

[2] L. Sheng, F. Yang, T. Xi, C. Lai, H. Ye, Influence of heat treatment on interface of cu/al bimetal composite fabricated by cold rolling, Composites Part B: Engineering 42 (6) (2011) 1468 - 1473.

[3] X. Li, G. Zu, P. Wang, Microstructural development and its effects on mechanical properties of al/cu laminated composite, Transactions of Nonferrous Metals Society of China 25 (1) (2015) 36 - 45.

[4] A. Abdollah-Zadeh, T. Saeid, B. Sazgari, Microstructural and mechanical properties of friction stir welded aluminum/copper lap joints, Journal of Alloys and Compounds 460 (1) (2008) 535 - 538.

[5] S. Madhusudan, M. Sarcar, N. Bhargava, Fabrication and characterization of aluminiumcopper composites, Journal of Alloys and Compounds 471 (1) (2009) $116-118$.

[6] H. Zhang, X. Dong, Experimental and numerical studies of coupling size effects on material behaviors of polycrystalline metallic foils in microscale plastic deformation, Materials Science and Engineering: A 658 (2016) 450 - 462.

[7] T. Sasaki, R. Morris, G. Thompson, Y. Syarif, D. Fox, Formation of ultra-fine copper grains in copper-clad aluminum wire, Scripta Materialia 63 (5) (2010) $488-491$.

[8] K. Rhee, W. Han, H. Park, S. Kim, Fabrication of aluminum/copper clad composite using hot hydrostatic extrusion process and its material characteristics, Materials Science and Engineering: A 384 (1) (2004) 70 - 76.

[9] Y. Guo, G. Qiao, W. Jian, X. Zhi, Microstructure and tensile behavior of cual multi-layered composites prepared by plasma activated sintering, Materials Science and Engineering: A 527 (20) (2010) 5234 - 5240.

[10] T. Jin, G. Li, Y. Cao, R. Xu, S. Shao, B. Yang, Experimental research on applying the copper-clad aluminum tube as connecting tubes of air conditioners, Energy and Buildings 97 (2015) $1-5$.

[11] L. Kuncicka, R. Kocich, K. Dvorak, A. Machackova, Rotary swaged laminated cu-al composites: Effect of structure on residual stress and mechanical and electric properties, Materials Science and Engineering: A 742 (2019) 743 - 750.

[12] R. Kocich, L. Kuncicka, P. Kral, P. Strunz, Characterization of innovative rotary swaged cu-al clad composite wire conductors, Materials and Design 160 (2018) $828-835$.

[13] W. Gluchowski, Z. Rdzawski, J. Domagala-Dubiel, J. Sobota, Microstructure and properties of multifibre composites, Archives of Metallurgy and Materials 61 (2) (2016) $911-916$.

[14] F. Moisy, A. Gueydan, X. Sauvage, A. Guillet, C. Keller, E. Guilmeau, E. Hug, Influence of intermetallic compounds on the electrical resistivity of architectured copper clad aluminum composites elaborated by a restacking drawing method, Materials and Design 155 (2018) $366-374$.

[15] E. Hug, N. Bellido, Brittleness study of intermetallic (cu, al) layers in copper-clad aluminium thin wires, Materials Science and Engineering: A 528 (22) (2011) $7103-7106$

[16] F. Moisy, X. Sauvage, E. Hug, Investigation of the early stage of reactive interdiffusion in the cu-al system by in-situ transmission electron microscopy, Materialia 9 (2020) 100633.

[17] H. Park, D. N. Lee, Effects of shear strain and drawing pass on the texture development in copper wire, in: Materials Science Forum, Vol. 408, 2002, pp. 637-642.

[18] H. Park, D. N. Lee, The evolution of annealing textures in 90 pct drawn copper wire, Metallurgical and materials transactions A 34 (3) (2003) 531. 
[19] X. Luo, Z. Song, M. Li, Q. Wang, G. Zhang, Microstructural evolution and service performance of cold-drawn pure aluminum conductor wires, Journal of Materials Science and Technology 33 (9) (2017) 1039 - 1043.

[20] K. Hanazaki, N. Shigeiri, N. Tsuji, Change in microstructures and mechanical properties during deep wire drawing of copper, Materials Science and Engineering: A 527 (21-22) (2010) 5699-5707.

[21] A. Gueydan, B. Domengès, E. Hug, Study of the intermetallic growth in copper-clad aluminum wires after thermal aging, Intermetallics 50 (2014) 34-42.

[22] R. Kocich, A. Macháčková, L. Kunčická, F. Fojtík, Fabrication and characterization of cold-swaged multilayered al-cu clad composites, Materials and Design 71 (2015) 36-47.

[23] W. N. Kim, S. I. Hong, Interactive deformation and enhanced ductility of tri-layered cu/al/cu clad composite, Materials Science and Engineering: A 651 (2016) 976-986.

[24] C.-Y. Chen, W.-S. Hwang, Effect of annealing on the interfacial structure of aluminum-copper joints, MATERIALS TRANSACTIONS 48 (7) (2007) 1938-1947.

[25] X. Feaugas, H. Haddou, Grain-size effects on tensile behaviour of nickel, AISI 316L stainless steel, Metallurgical Transactions 34A (2003) $2329-2340$.

[26] C. Keller, E. Hug, X. Feaugas, Microstructural size effects on mechanical properties of high purity nickel, International Journal of Plasticity 27 (4) (2011) $635-654$.

[27] S. Komura, Z. Horita, M. Nemoto, T. G. Langdon, Influence of stacking fault energy on microstructural development in equal-channel angular pressing, Journal of Materials Research 14 (10) (1999) 4044-4050.

[28] N. Q. Chinh, G. Horvath, Z. Horita, T. G. Langdon, A new constitutive relationship for the homogeneous deformation of metals over a wide range of strain, Acta Materialia 52 (12) (2004) 3555 - 3563.

[29] X. Luo, Z. Song, M. Li, Q. Wang, G. Zhang, Microstructural evolution and service performance of cold-drawn pure aluminum conductor wires, Journal of Materials Science and Technology 33 (9) (2017) 1039 - 1043.

[30] P.-A. Dubos, E. Hug, S. Thibault, M. Ben Bettaieb, C. Keller, Size effects in thin face-centered cubic metals for different complex forming loadings, Metallurgical and Materials Transactions A (2013) 1-10.

[31] I. Kovacs, N. Chinh, E. Kovacs-Csetenyi, Grain size dependence of the work hardening process in al99.99, physica status solidi (a) 194 (1) (2002) 3-18.

[32] M. Braunovic, L. Rodrigue, D. Gagnon, Nanoindentation study of intermetallic phases in al-cu bimetallic system, in: 2008 Proceedings of the 54th IEEE Holm Conference on Electrical Contacts, 2008, pp. 270-275.

[33] W. Zhou, L. Liu, B. Li, Q. Song, P. Wu, Structural, elastic, and electronic properties of al-cu intermetallics from first-principles calculations, Journal of Electronic Materials 38 (2009) 356-364.

[34] H.-J. Shin, H.-T. Jeong, D. Lee, Deformation and annealing textures of silver wire, Materials Science and Engineering: A 279 (1) (2000) 244 -253 .

[35] T. Baudin, A. L. Etter, M. H. Mathon, S. Jakani, P. Gerber, D. Solas, R. Penelle, Deformation and Recrystallization Textures and Microstructures in Cold-Drawn Copper, John Wiley and Sons, Ltd, 2007, Ch. 13, pp. 101-107.

[36] X. guang MA, J. Chen, Y. Yang, L. Li, Z. Chen, W. Yan, Temperature dependence of microstructure and texture in cold drawn aluminum wire, Transactions of Nonferrous Metals Society of China 27 (4) (2017) 763 - 770.

[37] A. Dashti, M. H. Shaeri, R. Taghiabadi, F. Djavanroodi, F. Vali Ghazvini, H. Javadi, Microstructure, texture, electrical and mechanical properties of aa-6063 processed by multi directional forging, Materials 11 (12) (2018) 2419.

[38] J.-M. Zhang, Y. Zhang, K.-W. Xu, V. Ji, Young's modulus surface and poisson's ratio curve for cubic metals, Journal of Physics and Chemistry of Solids 68 (4) (2007) $503-510$.

[39] G. Voyiadjis, C. Hartley, Residual-stress determination of concentric layers of cylindrically orthotropic materials, Experimental Mechanics 27 (1987) $290-297$.

[40] M. Sedighi, J. Joudaki, H. Kheder, Residual stresses due to roll bending of bi-layer al-cu sheet: Experimental and analytical investigations, 
The Journal of Strain Analysis for Engineering Design 52 (2) (2017) 102-111.

[41] R. Bullough, C. Hartley, Residual stresses in codeformed composite cylinders, Journal of Materials Processing Technology 45 (1) (1994) 281 $-286$.

[42] M. Ashby, C. Gandhi, D. Taplin, Overview no. 3 fracture-mechanism maps and their construction for fcc metals and alloys, Acta metallurgica 27 (5) (1979) 699-729.

[43] I.-K. Kim, S. I. Hong, Effect of heat treatment on the bending behavior of tri-layered cu/al/cu composite plates, Materials and Design 47 (2013) 590-598. 